\title{
Publisher Correction: Cellular and molecular pathobiology of heart failure with preserved ejection fraction
}

\author{
Sumita Mishra and David A. Kass (iD
}

Correction to: Nature Reviews Cardiology https://doi.org/10.1038/s41569-020-00480-6, published online 11 January 2021.

In the version of this article originally published online, in the top right-hand corner of Figure 2, the kinase next to STAT was incorrectly labelled as JNK instead of JAK. This error has been corrected in the HTML, PDF and print versions of the manuscript.

https://doi.org/10.1038/s41569-021-00516-5 I Published online 21 January 2021

(C) Springer Nature Limited 2021

\section{Publisher Correction: Reappraising the role of inflammation in heart failure}

Luigi Adamo, Cibele Rocha-Resende (D), Sumanth D. Prabhu and Douglas L. Mann (I)

Correction to: Nature Reviews Cardiology https://doi.org/10.1038/s41569-019-0315-x, published online 22 January 2020.

In the version of this article originally published online and in print, the protein high-mobility group box 1 (HMGB1) was incorrectly formatted as a citation to Box 1. This error has been corrected in the HTML and PDF versions of the manuscript.

https://doi.org/10.1038/s41569-021-00534-3 I Published online 12 March 2021

๑) Springer Nature Limited 2021 